\title{
KONSEP CINTA ILAHI (MAHABBAH) RABI'AH ADAWIYAH
}

\author{
Mudaimin \\ Institut Agama Islam Negeri (IAIN) Palu \\ Email: $\underline{\text { mudhatolisbang85gmail.com }}$
}

\section{Abstract:}

We need a handle on life, that is religion or belief that recognizes the existence of an all-powerful substance, whereas in daily life a person is required to maintain, improve, and improve the quality of faith and piety in the creator, to achieve that there are all several ways one of which is through the world of Sufism or commonly known as the mystical world. For attainment in the mystical world it can be done by way of meditation or spiritual practice. The pinnacle of the mystical world is mahaabah or divine love where these are the highest levels of attainment towards God. In this paper the author examine the theory of divine love (mahabbah) from the Sufi women who first expressed her love to God, namely Rabi'ah Adawiyah. This paper uses the type of library research, while the approach used is historical, philosophical. Data collection is done by the documentation method and analyzed by descriptive analysis method. According to Rabi'ah love is love that has no strings attached to it and does not expect a reward in the form of either reward or liberation of the law, but what is sought is only doing God's will and perfecting it.

Dalam kehidupan ini kita membutuhkan pegangan hidup yaitu agama atau keyakinan yang mengakui adanya zat yang maha kuasa, sedangkan dalam kehidupan sehari-hari seseorang dituntut menjaga, memperbaiki, dan meningkatkan kualitas iman dan takwa pada sang pencipta, untuk mencapai itu semua ada beberapa jalan salah sat unya adalah melalui dunia tasawuf atau biasa dikenal dengan dunia mistik. Untuk pencapaian dalam dunia mistik itu dapat dilakukan dengan cara meditasi atau latihan spiritual. Puncak dari dunia mistik adalah mahabbah atau cinta Ilahi dimana ini semua merupakan 
134 |Rausyan Fikr, Vol. 16 No. 1 Juni 2020: 133-162.

tingkat tertinggi dalam pencapaian menuju Allah. Dalam tulisan ini penulis menelaah teori cinta ilahi (mahabbah) dari tokoh sufi perempuan yang pertama kali mengemukakan kecintaanya pada sangkhalik yakni Rabi'ah Adawiyah. Penelitian ini menggunakan penelitian kepustakaan (library research). Adapun pendekatan yang digunakan adalah historis, folosofis. Pengumpulan data dilakukan dengan metode dokumentasi dan dianalisis dengan metode analisis deskritif. Menurut Rabi'ah cinta adalah cinta yang tidak ada pamrih di dalamnya dan tidak mengharapkan balasan baik yang berupa ganjaran maupun pembebasan hukum, tetapi yang dicari hanyalah melakukan keinginan Allah dan menyempurnakannya.

Keywords: Rabi'ah Adawiyah, Cinta Ilahi (Mahabbah).

\section{PENDAHULUAN}

Dalam kehidupan manusia membutuhkan pegangan hidup yaitu agama. Dalam diri manusia terdapat keyakinan yang mengakui adanya Zat yang maha kuasa, tempat memohon perlindungan dan pertolongan. Dalam kehidupan sehari-hari seseorang dituntut menjaga, memperbaiki, dan meningkatkan kualitas iman dan takwa pada sang pencipta. Untuk mecapai itu semua ada beberapa jalan di antaranya adalah melalui dunia tasawuf.

Dalam dunia tasawuf sering disebut sebagai dunia mistik, kata mistik disni terkadung sesuatu yang misterius yang mana dalam pencapaiannya tidak dengan cara biasa atau dengan akal tetapi harus dengan cara meditasi atau latihan spiritual, bebas dari ketergant ungan indera dan rasio. Mistik tidak bisa dijelaskan dengan filsafat, bahkan dengan penalaran pun tidak bias mengungkapkannya, hanya pengalaman rohani dan sprituAllah yang mampu sampai pada puncak kearifan dan dapat mendalaminya. Dalam arti yang luas, mistik bias juga didefinisikan sebagai cinta kepada yang mutlak. 
Mudaimin, Konsep Cinta Ilahi (Mahabbah) ...| 135

Perhentian terakhir di jalan mistik adalah mahabbah atau cinta. Mahabbah merupakan tingkat tertinggi dalam pencapaian menuju Allah, persoalan mahabbah adalah menyangkut aspek esoterik atau batin. Cinta atau mahabbah tidak dapat dipelajari melainkan adalah anugerah dari ilahi dan datang atas kehendaknya. Dengan demikian dalam mendapatkan maqam cinta itu tidaklah mudah, melainkan harus melalui jalan, stage-stage atau tanggatangga dan cobaan yang berliku-liku, dan cinta inilah yang mendasri iman.

Menurut Santo Agustinus orang dapat mengenal sesuatu hanya sesuai dengan cintanya kepadanya. Doa yang menurut hadits diucapkan oleh Rasulullah merupakan titik tolak yang baik: ya Tuhan, berilah aku cintamu dan cinta mereka yang mencintaimu, dan cinta yang membuatku mendekati cintamu, dan buatlah cintamu lebih ku cintai dari air sejuk. ${ }^{1}$ Cinta (mahabbah) menurut para ulama sufi adalah kehendak, yaitu kehendak-Nya untuk melimpahkan rahmat secara khusus kepada hamba sebagaimana kasih saying Allah bagi hamba yang dia kehendaki. Jadi mahabbah lebih khusus dari pada rahmat.

Dalam buku Asy-Syibli, Al-Ghazali berkata, Ahli mahabbah meneguk secawan anggur kecintaan, maka bumi dan negeri menjadi sempit bagi mereka. Metreka mengenal Allah dengan sebenarbenarmnya. Mereka tersesat dalam keagungannya. Mereka bingung dalam kekuasaannya. Mereka meneguk secawan anggur kecintaannya. Mereka tenggelam dalam lautan keakrabannya. Mereka berenang-renag dalam munajak kepadanya. ${ }^{2}$

Ibn Abd al-Shamad berkata, cinta adalah yang mendatangkan kebutaan dan ketulian. cinta membutakan segalanya kecuali

${ }^{1}$ Annemarie Schimmel. Dimensi Mistik Dalam Islam. (Jakarta: Pustaka Firdaus2003.), h.167

${ }^{2}$ Asy-Syibli. Menyingkap Hati Menghampiri Ilahi. (Bandung: Pustaka Hidayah 1999), h.42 
terhadap Yang Dicintai, sehingga orang tersebut tidak melihat apa pun kecuali Dia. Cinta membuatku tuli dari segala kecuali suaranya, Pernahkah cinta seaneh ini? Cinta membutakanku, dan hanya kepadanya semata aku memandang Cinta membutakan, dan karena tersembunyi, Membunuh. ${ }^{3}$

Dalam dunia tasawuf tak ada definisi yang pasti tentang cinta. Setiap sufi memberikan definisi yang berbeda dan tidak memungkinkan untuk menjelaskan semua definisi tersebut dalam penelitian ini. Karena itulah penelitian ini mencoba untuk menelaah teori cinta ilahi dari tokoh sufi perempuan yang pertama kali mengemukakan kecintaanya pada sangkhalik yakni Rabi'ah Adawiyah. Menurut peneliti sangat menarik mengkaji Rabia'ah Adawiyah, karena ialah seorang sufi wanita yang memilih menjalani hidup hanya dengan Sang Kekasih dan tak adalagi ruang di hatinya untuk mencintai yang selain Dia, karena pesona keindahan Sang Kekasih telah memabukkannya.

Berdasarkan uraian di atas, maka penulis tertarik untuk mengadakan penelitan tentang Konsep Cinta Ilahi (Mahabbah) Rabi'ah Adawiyah, melalui pendekatan sufisme dan psikologi. Metode yang digunakan dalam penulisan Jurnal ini adalah menggunakan beberapa metode penguraiyan dan penulisannya agar mendapat sasaran yang diinginkan, metode-metode tersebut antara lain "Penelitian kepustakaan (library research), karena data-data yang diperoleh adalah dari sumber-sumber tertulis, sedangkan Metode pendekatan yang digunakan adalah pendekatan historisfilosofis. Metode Metode pengumpulan data yang digunakan dalam penelitian ini adalah metode dokumentasi, yaitu metode yang mencari data mengenai hal-hal atau variabel-variabel yang berupa catatan, transkip, buku, surat kabar, majalah, notulen, dan sebagainya. Data primer yang digunakan dalam penelitian ini adalah

${ }^{3}$ Al-Kalabadzi. Ajaran Kaum Sufi. (Cet. I, Bandung: Mizan, 1993), h.138139. 
buku-buku karya tokoh yang diteliti. Sedangkan data sekunder adalah dokumen-dokumen dan buku-buku yang mengulas tentang tasawuf atau cinta Ilahi (Mahabbah) Rabia'ah Adawiah, dan bukubuku penunjang atau bahan pustaka yang dinilai relevan dengan objek yang akan diteliti. Metode Analis Data yang telah terkumpul kemudian dianalisis dengan menggunakan metode deskriptif.

\section{BIOGRAFI RABIA'AH ADAWIYAH}

\section{Sejarah singkat Rabi'ah Adawiyah}

Rabi'ah Adawiyah adalah Salah seorang penyair sufi perempuan yang terkenal pada abad ke- $2 \mathrm{H}$, atau ke- $8 \mathrm{M}$, di basrah, Iraq, Seseorang perempuan yang menghijabi dirinya dengan keikhlasan Agama, seseorang yang selalu membara oleh api cinta dan kerinduan kepada Tuhan. Seseorang yang terpikat hatinya dan selalu dekat dengan tuhannya, seseorang yang relah meninggalkan hidupnya demi menyatu dengan sang khaliq.

Nama lengkapnya adalah "Ummul Khair binti Ismail Adawiyah al-Qasisiyah. Dilahirkan sekitar tahun 95 H/717 M, di Basrah-Iraq. Berasal dari suku Atiq, dan ayahnya bernama ismail". ${ }^{4}$ Orangtua Rabi'ah telah memiliki tiga orang putri sebelumnya, oleh sebab itulah putrinya kali ini diberi nama Rabi' ah, yang berarti putri keempat. Ia dilahirkan ditenga keluarga miskin. Pada malam kelahirannya tidak terdapat minnyak dirumahnya, sehingga tidak ada penerangan apapun, juga tak ada sehelai kain untuk menyelimuti sang bayi. Kemudian istrinya meminta kepada Ismail agar pergi kerumah tetangga untuk meminta minyak agar bisa menyalakan lampu. Tetapi Ismail telah bersumpah bahwa ia tida akan meminta sesuatu dari manusia lain (seorang sufi hanya akan bergantung kepada Tuhan untuk memenuhi kebutuhannya). Maka pergilah ia sambil pura-pura menyentuhkan tangannya kepintu rumah

4 Syamsun Ni'am, Cinta Ilahi Perspektif Rabi'ah Adawiyah dan Jalaluddin Rumi. (Cet. IV, Surabaya: Risalah Gusti, 2001), h. 17 
tetangganya, lalu kembalih kerumahnya lagi. Kemudian ia berkata pada istrinya, bahwa mereka tidak mau membuka pintunya. Istrinya menangis denga sedih. Dalam keadaan serba memprihatinkan itu, suaminya hanya dapat menekurkan kepala dan terlena. ${ }^{5}$

"Rabi' ah tumbuh dan berkembang dalam lingkungan keluarga yang shaleh dan zuhud. Hal ini dibuktikan dengan kejujuran dan kesalehan ayahnya dalam berprilaku yang begitu hati-hati denga sesuatu yang belum jelas asal-usulnya". 6 Menjelang dewasa, orangtuah Rabi'ah meninggal dunia. Jadilah ia anak yatim piatu. Kelaparan melanda basrah dan semua saudaranya terpisah.

Suatu hari Rabi'ah berjalan keluar kota, kemudian seseorang merenggutnya dan menjualnya sebagai budak. Suatu malam, tuannya terbangun dari tidurnya nampak melalui jendelah kamarnya

${ }^{5}$ Diriwayatkan: di dalam tidur Ismail ia bermimpi melihat Nabi saw, kemudian Nabi berkata: "Janganlah engkau bersedih, karena bayi perempuan yang baru dilahirkan itu adalah ratu kaum perempuan dan akan menjadi penegah bagi 70 ribu orang diantara kaumku. Besok pergilah engkau menghadap Isa al-Zadan, Gubernur Basrah. Diatas kertas tuliskan kata-kata berikut, setiap malam engkau mengirim selawat seratus kali kepadaku, dan setiap malam Jum'at empat ratus kali. Tetapi malam Jum'at ini engkau lupa melakukannya. Sebagai penembus kelalaianmu itu, makaberikan kepada orang ini empat ratus dinar yang telah engkau proleh secara halal”. Ketika terjaga dari tidurnya, ayah Rabi'ah mengucurka air mata. Ia pun bangkit dan menulis seperti apa yang telah dipesankan Nabi saw kepadanya, dan mengirimkannya kepada gubernur melalui pengurus rumah tangga istana. Setelah gubernur membaca surat tersebut, maka ia berkata: "Berikan dua ribu dinar kepada orang-orang miskin sebagai tanda terimakasi sebab Nabi telah sudi mengingatku. Kemudian berikan empatratus dinar kepada orang tua ini dan katakanlah pedanya bahwa aku ingin ia menghadapku supaya aku dapat bertemu dengannya. Tetapi aku rasa tidaklah tepat jika orang seperti itu harus datang kepadaku, akulah yang akan datang kepadanya dan mengusap penderitaannya denga jenggotku". https://mojok.co/miq/esai/kelahiran-dan-kematian-rabiah-al-adawiyyah/ diakses pada tanggal 16 Mei 2020.

${ }^{6}$ Muhammad Roy, Tasawuf Madzab Cinta, (Cet. I, Yogyakarta: Penerbit Lingkaran 2009), h. 7 
Rabi'ah sedang sujud beribadah, dan diatas kepalanya terlihat lentera yang sangat terang hingga menyinari seluruh rumah. Melihat peristiwa aneh tersebut, tuan Rabi'ah merasa ketakutan, dan ia kembali ketempat tidurnya semula, dan duduk termenung hingga fajar menyingsing. Kemudian memanggil Rabi'ah, dan membebaskannya". ${ }^{7}$

Kemudian Rabi' ah pergi mengembara di padang pasir. Setelah beberapa saat ia tinggal di padang pasir, ia menemukan tempat tingal. Ditempat itulah ia menghabisikan seluruh waktunya untuk beribadah. $^{8}$

Menurut Rabi'ah bahwa dunia ini tak lebih dari sekedar alat dan bukan tujuan. Sementara itu perjalanan hidup masih jauh dan tujuan sebenarnya adalah melampaui dunia benda-benda serta menembus ke arah Tuhan. Kesempurnaan dan berbagai keutamaan jiwa Rabi'ah berkembang jauh melampaui kebanyakan sufi pada kurun waktu itu, kemudian menjadikannya terkenal sebagai "Mahkota kaum pria" (Taj alRijial). ${ }^{9}$

Banyak yang ingin melamar Rabi'ah namu semuanya ia tolak, Ia mengambil keputusan tersebut di karenakan menurutnya, denga tidak menikah itulah dia dapat melakukan pencarian tanpa ada hambatan. Menurut Rabi'ah dengan tidak menerima lamaran itu perjalanan menuju Tuhan akan berjalan dengan baik tampa mendapat rintangan. Ia pernah memanjatkan do'a; "Ya Allah, aku berlindung kepada-Mu dari segalah perkara yang menyibukkanku untuk menyemba-Mu". ${ }^{10}$

Penulis Tadzkirat al-Auliya, Fariduddin Aththar perna memaparkan bahwa Hasan al-Bashri perna bertanya kepada Rabi'ah,

\footnotetext{
${ }^{7}$ M. Fudoli Zaini, op.cit. h. 4

${ }^{8}$ Margaret Smith, Rabi'ah: Pergulatan Spiritual Permpuan (Cet. 1, Surabaya: 2001)h. 9

${ }^{9}$ Ibid. h. 25

${ }^{10}$ Mufidul Khoir, Rahasia Para Sufi (Cet. II; Yogyakarta, Republika, 2007), h. 125
} 
'Apakah engkau aka menikah?” Rabi'ah menjawab, "Pernikahan merupakan keharusan bagi orang yang mempunyai pilihan. Sedangkan aku tidak mempunyai pilihan dalam hatiku. Aku hanya untuk Tuhanku, dan taat pada perintah-Nya". ${ }^{11}$

Di antara mereka yang melamar Rabi' ah adalah, Abdul Wahid bin Zayd, yang terkenal dengan kezuhudan dan kesucian hidupnya, seorang teolog, dan ulama. Rabi'ah tidak menyambut lamaran itu, tetapi malah menjaukan diri darinya. Muhammad bin Sulaiman alHasyimi, seorang Abbasiyah dari Basrah. Ia mengajukan mahar perkawinan sebesar seratus ribu dinar dan menulis surat kepada Rabi'ah bahwa ia memiliki pendapatan sebanyak sepuluh ribu dinar tiap bulan dan akan memebrikan semuanya kepada Rabi'ah. Tetapi dijawab oleh Rabi'ah, "aku sungguh tidak merasa senang bahwa engkau akan menjadi budakku, dan semua milikmu akan kau berikan keppadaku, atau enkau akan menarikku dari Allah meskipun hanya untuk beberapa saat". ${ }^{12}$

Kisah lain tentang laki-laki yang melamar Rabi'ah adalah seorang gubernur yang menulis surat kepada rakyat Basrah agar mencarikannya seorang istri. Seluruh rakyat setuju kepada Rabi'ah, kemudian gubernur itu menunjukan lamarannya melalui sepucuk surat, maka dijawab oleh Rabi'ah:

"Penolakan terhadap dunia ini adalah perdamaian, sedangkan nafsu terhadapnya akan membawa kesengsaraan. Kendalikanlah nafsumu dan jangan biarkan orang lain mengendalikan dirimu. Bagimu, pikirkanlah hari kematianmu, sedangkan bagiku Allah dapat memberiku semua apa yang telah engkau tawarkan itu dan bahkan berlipat ganda. Aku tidak suka dijauhkan dari Allah walaupun hanya sesaat. Karenanya selamat tinggal". ${ }^{13}$

\footnotetext{
${ }^{11}$ Syamsun Ni'am, op.cit., h. 24

${ }^{12}$ Margaret Smith, op.cit, h. 14

${ }^{13}$ Ibid, h. 14
} 
Dalam kisah ini juga menyatakan sebuah pinangan yang disampaikan oleh Hasan al-Bashri, sahabat Rabi'ah, tetapi lamaran it upun ditolak, tetapi secara kornologis hampir tidak mungkin Hasan al-Bashri meminang Rabi'ah, karena ia dikisahkan meninggal lebih dari tujupuluh tahun sebelum kematian Rabi'ah munkin kisah ini menceritakan pinangan yang disampaikan oleh orang lain.

\section{Petualangan Intelektual Rabi'ah Adawiyah}

Dari riwayat menyatakan bahwa sejak kecil Rabi'ah senang sekali menghafal al- Qur' an dan dia juga seorang yang berbudi luhur, sopan, santun, serta berpenampilan sederhana, dan ingatannya sangat kuat. Hal ini menunjukkan bahwa sesunggunya Rabi'ah adalah seorang sufi yang cerdas.

Dari beberapa literatur yang ada, tidak ditemukan tentang bagaimana proses perjalanan intelektual Rabi'ah secara pasti, hanya saja ada beberapa orang yang dianggap sebagai guruh, murid dan sekaligus teman berdiskusi Rabia'ah. Mereka sering berkunjung keruma Rabi' ah baik siang maupun malam. Antara sahabat dan juga merupakan guru Rabi'ah antaralain: Hasan al-Bashri, di setiap pembahasan riwayat hidup Rabi'ah, selalu menghubung-hubungkan dengan Hasan al-Bashri. Digambarkan bahwa Rabi'ah adalah seseorang sahabat, murid, sekaligus pengikutnya.

Sahabat Rabi'ah lainnya, yang merupakan teman sepemikiran adalah Sufyan ats-Tsuri muncul dalam hampir semua biografi Rabi'ah, sebagi seorang sahabat yang sering berkunjung kerumah Rabi'ah dan banyak diantara ajarannya itu dihubung-hubungkan denga Rabi'ah sebagai hasil dari diskusi mereka berdua. ${ }^{14}$ Diriwayatkan juga bahwa adanya hubungan antara Rabi'ah dan Dzun Nun al-Mishri, salah seorang pelopor ajaran sufi, khususnya tentang doktrin ma'rifat.

14 Johan Jafar, Mengenal Sosok Sufi Wanita, Rabiah, (onlaine)www.cinta ilahi.com) diakses pada tanggal 22 Mei 2020 
142 |Rausyan Fikr, Vol. 16 No. 1 Juni 2020: 133-162.

Sahabat lainnya adalah Abdul Aziz bin Sulayman abu arRasibi dari Basrah, seoarang zuhud dan pengabdi yang disebut oleh rabi'ah dengan sebutan "pimpinan Pengabdi". Seseorang sahabat yang juga sering berkunjung dan membahas berbagai masalah adalah shalih bin Abdul aziz, Kitab bin Hari, seorang sufi Syi'ah, dan Malik bin Dinar, seseorang zahid terkenal.

Rabi' ah juga tidak memiliki murid yang secara resmi dia didik dan kemudian menjadi penerus perjuangannya, Rabi'ah hanya memiliki banyak teman yang sering berdiskusi, mendengarkan ajaran-ajaran Rabi'ah, dan mendengarkan do'a-do'anya, Sehingga dalam penelusuran penulis tidak menemukan satupun buku karya rabi'ah Adawiyah bahkan beliau tidak meninggalkan ajaranya secara tertulis langsung dari tangannya. Pemikiran Rabi'ah Adawiyah dikenal melalui pengikut-pengikutnya yang baru ditulis beberapa lama setelah kematiannya.

\section{Sekilas tentang Riwayat Wafatnya Rabi'ah Adawiyah}

Ibn al-Jawzi dalam shifah al-Shafwah menuturkan kisah berikut dari Muhammad Ibn 'Amr: ketika aku menemui Rabi'h, ia suda tua berusia delapan pulu tahun, renta dan rapuh seperti kulit kering. Tampaknya, jika enkau menyentuhnya, ia akan rontok berkeping-keping. Di dalam rumahnya, aku melihat hanya ada tikar dari bambu Persia setinggi dua meter. Atap rumahnya adalah ranting-ranting pohon palem. Ada juga sebuah kendi air dan sehelai kain wol di samping tempat tidur dan tempat shalatnya. Selain itu ada sehelai tikar anyaman tempat ia meletakkan kain kafannya. Manakalah disebut-sebut tentang kematian di hadapannya, ia gemetar dan tampak menggiggil ketakutan. ${ }^{15}$

Rabi'ah menjalani hidup hingga usia lanjut. Beliau wafat pada tahun $185 \mathrm{H} / 801 \mathrm{M}$, dalam usianya yang ke sembilan puluh tahun. Sedangkan tempat wafatnya dan makamnya tidak diketahui secara

${ }^{15}$ Dr. Javad Nurbakhsh, Op.cit., h. 31 
pasti. Ada yang menyebutkan ia dikuburkan di Jarusslem (al-Quds al-Syarif) diatas sebuah bukit. Tetapi sumber yang lebih kuat menyebutkan bahwa Rabi'ah wafat di Basrah, daerah Syam (syiria). Munkin makam yang ada di Jarussalem adalah makam Rabi'ah alShamiyah. ${ }^{16}$

Dalam karyanya tadzkirah al-Awliaya', Aththar menulis tentang kemurahan ruhanianya, mengenai wafatnya Rabi'ah, para syaikh sufi besar menyatakan, Rabi'ah masuk kedunia ini pergi ke akhirat. Ia tidak pernah mengagun-agunkan atau membanggabanggakan dirinya di hadapan Allah, tidak pernah menginginkan sesuatu apapun, tidak pernah berkata lakukan sesuatu untukku, atau berikan aku ini. ${ }^{17}$

\section{Pemikiran Rabi'ah Al-Adawiyah}

Semasa hidup Rabi'ah Adawiyah tidak pernah mendapatkan pendidikan formal. Kecintaan kepada Allah dilandasi pengalaman hidupnya yang keras, dan berdasarkan naluri yang ia rasakan. Kondisi hidup yang dialami mendasarinya menempuh jalan cinta. Sejak kecil Rabi'ah mendapatkan kehidupannya di dunia sangat kejam. Saat ia sebatang kara, ia tidak menemukan orang yang berbuat baik. Yang ia temukan hanyalah orang yang menyakiti dan menjual orang lain sebagai dagangan, serta orang yang memelihara orang lain sebagai budak, dan Rabi'ah merupakan sala satu korban dari kejahatan tersebut. Ia tidak menemukan pelindung dan penolong dalam kesendiriannya. "Bekal agama yang diwarisi oleh orang tuanya membeuat ia menyimpulkan bahwa hanya Allah yang benar-benar agung dan dapat diharapkan melindung dan menolongnya". ${ }^{18}$

${ }^{16}$ Safari MS \& Otto Sukatno, Mahabba: Cinta Rabi'ah Adawiyah (Cet. I; Bandung. Risalah Gusti 2001), h. 36

${ }^{17}$ Dr. Javad Nurbakhsh, loc.cit, h. 31

18 Safari MS \& Otto Sukatno, Mahabba: Cinta Rabi'ah Adawiyah (Cet. I; Bandung: Risalah Gusti 2001) h. 460 
144 |Rausyan Fikr, Vol. 16 No. 1 Juni 2020: 133-162.

Secara singkat definisi cinta menurut rabi'ah yang sering diajarkan adalah cinta seorang hamba kepada Allah Tuhannya. Ia mengajarkan bahwa yang pertama, cinta itu harus menut up yang lain selain sang kekasih atau yang dicintai, yaitu bahwa sufi harus memalingkan punggungnya dari dunia dan segala daya tariknya. Ia harus memisahkan dirinya dari sesama mahluk ciptaan Allah, agar tidak dapat menarik diri dari sang pecinta, ia bahkan harus bangkit dari semua keinginan nafsu duniawi dan tidak memberi ruang adanya kesenangan dan tidak juga kesenangan yang dapat mengganggu perenungannya pada yang suci. Menurut Rabi'ah, tuhan dipandang penuh dengan kecemburuan-Nya, diman hanya dia sendiri yang harus dicintai.

Yang kedua, ia mengajarkan bahwa cinta ini, yang langsung ditujukan kepada Allah dan mengesampingkan yang lainnya, harus tidak pamrih sama sekali dan tidak mengharapkan balasan baik yang berupa ganjaran maupun pembalasan hukuman, tetapi yang dicari hanyalah melakukan keinginan Allah dan menyempurnakannya, sehingga dia diagungkan. "Hanya bagi seseorang hamba yang mencintai seperti inilah Allah dapat menyatakan dirinya sendiri di dalam keindahan yang sempurna dan hanya melalui jalan cinta penginkaran diri inilah jiwa yang mencintai pada akhirnya mampu menyatu dengan yang dicintai dan dalam kehendak itulah akan ditemui kedamaian". ${ }^{19}$

Bagi Rbi'ah, dengan mahabbatullah, setelah melewati tahaptahap sebelumnya, seorang sufi mampu meraih ma'rifat sufistik dan hati yang telah dipenuhi oleh rahmat-Nya. Pengetahuan itu datang langsung sebagai pemberian dari Allah tanpa hijab (hal). Dengan mata yang telah dipenuhi oleh ma'rifat, para sufi akan mampu menatap penyaksian itu, dan memandang-Nya denga asyik terpesona dalam penyatuan dengan Yang Suci. Itulah tujuan akhir

19 Margaret Smith, Rabi'ah: Pergulatan Spiritual Permpuan (Cet. 1, Surabaya: 2001) h. 122-123 
dari pencarian atau pengembaraan jiwa, akhir dari jalur, tercapai sudah, tidak dengan penghancuran, tetapi kekhusyukan dan perubahan, sehingga jiwa akan diubah ke dalam penyaksian suci, dan menjadi bagian dari Allah itu sendiri, didalam tempat dan kehidupan bersama-Nya untuk selamanya.

Rabi'ah Adawiyah secara praksis membagi cinta kedalam dua bagian: hubb al-hawa dan hubbun liannaka ahlun lidzaka, pertama, cinta diri sendiri karena selalu ingat kepada Yang Tercinta (Tuhan) yang bersedia membukakan tabir-Nya kepada sang pecinta, dan ini merupakan hal, karena terbukanya tabir antara hamba dan Tuhan merupakan kehendak dan anugerah Tuhan ${ }^{20}$

Bagi Rabi'ah Adawiyah objek cintanya hanya Allah semata, di dalam hatinya tiada tempat bagi yang lain, sampai-sampai tidak ada tempat untuk mencintai Rasul dan juga tidak ada tempat dihatinya untuk membenci syetan. Rabi'ah menutup hatinya untuk mencintai makhluk, dan juga menutup hatinya untuk merasakan perasaan lain selain Allah Semata. Karena itulah ia tidak perna menika. Baginya menika hanya akan menyibukkan hati dan pikiran dari mengingat Allah. Ketika Rabi' ah ditanya tentang kecintaannya kepada Rasulullah, maka ia menjawab: "aku, demi Allah, sangat mencintainya, namun cintaku kepada al-Khaliq telah memalingkan perhatiaku dari mencintai makhluk". ${ }^{21}$

Untuk mencapai mahabbatullah, maqam yang ia tempuh ant ara lain: tobat, sabar, dan syukur, raja dan khauf, fakir dan zuhud, mahabbah dan ma'rifat.

\section{AJARAN TASAWUF RABIA'AH ADAWIYAH}

Rabi'ah Al-Adawiah tercatat dalam perkembangan mistisme Iskam sebagai peletak dasar Tasawuf berdasarkan cinta kepada

${ }^{20}$ Khoir Mufidul, Rahasia Para Sufi. (Yogyakarta: SKETSA, 2007), h. 146

${ }^{21}$ Syekh 'Ustman Al-Khubari, Kisah Cinta Rabi'ah (Cet.VII; Jogyakarta, Diva Press 2011), h. 9 
Allah. Dalam perjalanan spiritualnya, seorang salik telah menempuh berbagai cara dan pendekatan dalam upaya mendekatkan diri kepada Allah swt. Rabi'ah Al-badawiah menyebutkan bahwa pada awal perkembangannya upaya ini muncul dalam bentuk kehidupan duniawi yang membawa kelalaian terhadap pelaksanaan taat dan menghalangi usaha mencari keridahan-Nya. Pada tahap ini, usaha mereka masih didasari perasaan takut (khauf) dan pengharapan (raja). Salah satu tokohnya adalah hasan al-Bashri, dan kemudian disusul Rabi'ah yang meningkatkan kehidupan zuhud itu dengan unsur baru, yaitu cinta (mahabbah) dengan pengertiannya yang hakiki dan sempurna. ${ }^{22}$

Rabiah Al-Adawiah adalah seorang toko istimewah mengingat penekanannya dalam beberapa pandangan yang kemudiaan memainkan peranan penting pengelaborasian doktrin cinta ilahi. Sebagai mana yang ditulis oleh M. Smith, meski Rabi'ah bukanlah sufi pertama yang mengetahui bahwa jalan kepada tuhan harus ditempuh melalui cinta, namun dia mungkin yang pertama dalam menekankan doktrin itu dan memadukannya dengan doktrin kasyf, tersingkafnya sang kekasih di hadapan pecinta-Nya pada akhir perjalanan. Rabi'ah juga termasuk tokoh pertama yang berpegang pada doktrin cinta tulus kepada tuhan yang pengekpresiannya melalui pelaksanaan kehendak tuhan. ${ }^{23}$

Cintanya kepada ilahi adalah cinta yang agung yang menampakka keindahan dalam bentuknya yang tertinggi, amat indah dan mulia, cinta api dalam sekam yang makin lama makin membara dan menyalah, untuk kemudian menerangi seluruh hidupnya dan membuatnya dalam damai.

\section{Makna Cinta}

${ }^{22}$ Dr, Abu al-Wafa' al-Ghanimi al-Taftazani, Sufi Dari Zaman ke Zaman, (Cet, I. Bandung, Penerbit Pustaka, 1406 H-1985 M), h. 25

${ }^{23}$ M. Taufik, Belajar Mencintai dan Dicintai Allah Dari al-Ghazali (Skripsi- IAIN Palu), h. 45 
Rabi'ah telah memperluas makna atau lingkup cinta ilahi. Ia dulunya mencintai Allah karena mengharapkan surga-Nya, atau takut neraka-Nya, sehingga ia selalu berdo'a: " oh tuhan. Apakah engkau akan membakar hamba-Mu di dalam neraka, yang hatinya terpaku pada-Mu, dan lidahnya selalu menyebut-Mu, dan hamba yang selalu takwa kepada-Mu?" setelah menyadari bahwa cinta seperti itu adalah cinta yang teramat sempit, ia meningkatkan dirinya, sehingga ia luluh dalam cinta ilahi (al-hubb al-ilahi). Ia mencintai Allah karena Allah patut dicintai, bukan karena takut nerakanya atau mengaharap surga-Nya. Dengan pendirian, ia ingin mengatakan bahwa ia tidak ingin menjadi "pekerja perempuan yang tidak baik", seorang yang meninggalkan pekerjaan yang tidak baik, lalu melakukan kebaikan dengan mengharapkan ganjaran, yaitu surga". 24

Fariduddun Aththar meriwayatkan bahwa Rabi'ah selalu menangis, sehingga orang bertanya kepadanya, "mengapa engkau menangis, apakah engkau menderita karena-Nya? Rabi'ah menjawab, "Oh, nasib penderitaan dan sakit yang aku derita tak seorangpun dokter akan mampu mengatasinya. Mereka tak akan mampu menolongku menhilangkan derita ini, kecuali jika hapanku telah terwujud di alam yang lain, yaitu ketika aku melihat wajahNya yang maha mulia. Al-Kalabadzi meriwatkan, ada sekolompok orang datang kepada rabi'ah untuk menanyakan kesehatannya. Mereka bertanya, "bagaimana keadaanmu? Rabi' ah menjawab, demi Allah sku tidak tahu penderiataan yang akuderita sekarang ini. Aku merasa seolah-olah digoda oleh surga, sehingga hatiku hampir tertarik padanya. Namun aku merasakan seolah-olah mencelah diriku". ${ }^{25}$

${ }^{24}$ Syamsun Ni'am, Cinta Ilahi Perspektif Rabi'ah Adawiyah dan Jalaluddin Rumi. (Cet. IV, Surabaya: Risalah Gusti, 2001), h.26-27

${ }^{25}$ Ibid, 28 
148 |Rausyan Fikr, Vol. 16 No. 1 Juni 2020: 133-162.

Tampak jelas bahwa cinta Rabi' ah kepada Allah begitu penuh meliputi dirinya, sehingga sering membuat dirinya tidak sadrkan diri karena hadir bersama Allah. Dari uraian tersebut dapat diikhtiarkan bahwa Rabi'ah Adawiyah pada abad kedua hijriyah, merintis aliran asketisisme (kezuhudan) dalam Islam berdasarkan cinta kepada Allah (mahabbatullah). Sementar sufi sebelumnya, yaitu Hasan alBashri merintis aliran askesisme dalam Islam yang didasarkan oleh rasa takut (khaf) kepada Allah. ${ }^{26}$

Menurut al-Taftazani, 'Rabi' ah tidak hanya mengenalkan kaa cinta semata, namun ia juga yang pertama-tama menganalisis pengertian cinta dan menguraikannya, cinta yang tulus ikhla dan cinta yang berdasarkan permintaan akan sesuatu dari Allah. Analisis ini cukup detail karena berdasarkan rasa dan penghayatan secara langsung". ${ }^{27}$

Ketika rabiah ditanya tentang cinta (mahaabah), dia menjawab, "antara orang yang mencintai dan orang yang dicintai tidak ada jarak sehingga tidak ada pemisah diantara yang mencintai dan yang di cintai. Ia adalah pembicaraan tentang kerinduan dan penyifatan tentang perasaan. Barang siapa yang merasakan cinta berarti ia telah mengenal, dan barangsiapa yang menyifati, maka tidaklah ia bersifat dengan-Nya. Bagaimana engkau menyifati sesuatu padahal engkau sendiri ghaib dari sisin-Nya, terhadap wujud dan kehadiran-Nya engkau pandai, dengan kesadaranmu engkau mabuk, untuk memutuskan perhatianmu kepada-Nya engkau suda penuh, dalam bergembira dengan-Nya, engkau bingun. Kehebatan menjadikan lidah keluh untuk menyebutkan, ketercegangan menjadikan akal terikat (terbelenggu) untuk mengakui dan kebingungan menjadikan hati terhenti untuk menyatakan. Maka disana hanya kebingungan menjadikan hati terhenti untuk menyatakan. Maka disana hanya kebingungan yang abadi, hati yang

\footnotetext{
${ }^{26}$ Ibid, 29

${ }^{27}$ Ibid,
} 
lemah dan rahasia yang sempurna. Sedangkan cinta dengan segalah kekuasaanya menjadi penentu dalam hati" 28 .

Secara singkat definisi menurut Rabi'ah yang sering di ajarkan adalah cinta seorang hamba kepada Allah tuhannya. Ia mengajarkan bahwa yang pertama, cinta itu harus menutup yang lain selain sang kekasih atau yang dicintai, dimana sufi harus memalingkan pandangannya dari duniah dan segalah daya tariknya. Ia harus memisahkan dirinya dari semua ciptaan Allah, agar tidak dapat menarik diri dari sang pecinta, ia bahkan harus bangkit dari semua keinginan nafsu duniawih dan tidak memberi ruang adanya kesenangan dan tidak juga kesengsaraan yang dapat mengganggu perenungannya pada yang suci Tuhan semesta alam. Menurut Rabi'ah, tuhan dipandang penuh dengan kecemburuan-Nya, dimana hanya dia sendiri yang harus dicintai.

Yang kedua, ia mengajarkan kita bahwa cinta yang langsung ditujukan kepada Allah dan mengesampingkan yang lainnya, tidak ada pamrih sama sekali dan tidak mengharapkan balasan baik yang berupa ganjaran maupun pembebasan hukuman, tetapi yang dicari hanyalah melakukan keinginan Allah dan menyempurnakannya, sehingga dia diagunkan. "Hanya bagi seorang hamba yang mencintai seperti inilah Allah dapat menyatakan dirinya sendiri di dalam keindahan yang sempurna dan hanya melalui jalan cinta pengingkaran diri inilah jiwa yang mencintai pada akhirnya mampu menyatu dengan yang dicintai dan di dalam kehendak itulah akan ditemui kedamaian". ${ }^{29}$

Rabi'ah dalam sala satu syairnya mengatakan, "harapanku adalah penyatuan dengan-Nya, sebab itulah tujuan dari keinginanku", dan ia berkata pada Hasan al-Bashri, "Keberadaanku

${ }^{28}$ Muhammad Bin Asy-Syarif, Nilai Cinta Dalam Al-Qur'an (Solo; PT. Serangkai Pustaka Mandiri 2003)h. 31

${ }^{29}$ Margaret Smith, Rabi'ah: Pergulatan Spiritual Permpuan (Cet. 1, Surabaya: 2001), h.122-123 
telah tiada dan jati diriku pun telah lenyap. Aku telah menjadi satu dengan-Nya dan secara keseluruhan telah menjadi satu bagian dengan-Nya". ${ }^{30}$

Pada dasarnya Rabi'ah sendiri sulit untuk mendefinisikan makna cinta yang sebenarnya, sebagaimana yang dikatakan oeh rumi, bahwa sesunggunya cinta hanya dapat dirasakan, dan tidak dapat diberikan maknanya. Ia mengatakan, "Apakah yang kuceritakan tentang cinta, ketika ku alami sendiri cinta itu, aku malu lantaran pembicaraan itu". Meskipun demikian, cinta dapat dirasakan pengaruhnya.

\section{Macam-macam Cinta}

Banyak kalangan para tokoh sufi maupun teolog yang membagi cinta, baik secara umum maupun secara khusus. Pendekatan yang digunakan pun berbeda-beda.

Bilah dilihat dari ungkapan-ungkapan cinta syair-syairnya, Rabi'ah al- Adawiyah secara Praksis membagi cinta kedalam dua bagian, yaitu: hubb al-hawa dan hubbun liannaka ahlan lidzaka. ${ }^{31}$ Al-Ghazali mengatakan bahwa:

"Yang dimaksud hubb al-hawa adalah cinta kepada Allah karena kebaikan dan kenikmata-kenikmatan yang dianugrahkan Allah kepada Rabi'ah. Dan Rabi'ah mencintai Allah, karena ia adalah zat yang berhak mendapat kecintaan, karena keindahan dan keagungan-Nya yang tersingkap untuk Rabi'ah".32

Sedangkan menurut al-Taftazani:

\footnotetext{
${ }^{30}$ Ibid. h. 124

${ }^{31}$ Ibid. h. 124

${ }^{32}$ Asfari MS \& Otto Sukatno, op.cit. h.61
} 
Mudaimin, Konsep Cinta Ilahi (Mahabbah) ...| 151

"Dalam lirik itu Rabi' ah mengklasifikasikan cinta Ilahi dalam dua jenis. Pertama, cinta rindu yang didefinisikannya dengan cinta karena hanya kau yang ku kenang selalu bukan selain$\mathrm{Mu}$. Kedua, cinta yang disebut dengan cinta karena kau layak dicintai yaitu karena kau singkapan tirai sampai kau nyata bagiku". ${ }^{33}$

Dengan demikian dapat disimpulkan bahwa Rabi'ah Adawiyah telah merumuskan cintanya kedalam dua macam cinta, yaitu:

a. Cinta diri sendiri (hubb al-hawa) karena selalu ingat kepada yang tercinta (Allah).

b. Cinta Allah (hubbun liannaka ahlun lidzaka) dimana keadaan yang tercinta (Tuhan) yang bersedia membukakan tabir-Nya kepada sang pecinta.

\section{Objek Cinta}

Allah adalah cahaya dari segala cahaya, baik yang ada di langit maupun yang ada di bumi. Cinta sejati adalah bilamana seluruh dirimu kau serahkan pada kekasihmu (Allah), hingga tidak tersisa sama sekali, dan hendaklah engkau cemburu bila ada orang yang mencintai kekasihmu melebihi cintamu kepada-Nya.

Diriwayatkan bahwa Allah telah mewahyukan kepada Nabi Dawud as, "Aku telah melarang cinta untuk-ku memasuki hati manusia jika cinta kepada selain aku juga punya tempat di dalamNya." Dalam versi lain dikatakan "Berdustalah orang yang mengatakan cinta kepada-Ku, namun bila malam telah tiba, matanya telah terkatup tidur (tidur nyenyak) dan tidak beribadah kepadaku". ${ }^{34}$

Begitu pula Rabi'ah Adawiyah menyatakan bahwa objek cinta hanyalah Allah semata, tiada yang lain. Di dalam hatinya tiada tempat bagi yang lain. Di dalam hatinya tidak ada tempat bagi yang

\footnotetext{
${ }^{33}$ Ibid. h. 62

${ }^{34}$ Syamsun Ni'am, op.cit. 126
} 
lain. Sampai-sampai tidak ada tempat untuk mencintai Rasul dan juga tidak ada tempat di hatinya untuk membenci syetan. Seseorang pernah bertanya kepada Rabi'ah:

"Bagaimana cintamu kepada Rasulullah saw?" Rabi'ah menjawab, "Aku, demi Allah, sangat mencintainya, namun cintaku kepada al-khaliq telah memalingkan perhatianku dari mencintai makhluk." Pada saat yang lain Rabi'ah juga pernah ditanya, "Wahai Rabi'ah apakah engkau mencintai Allah?" Rabi'ah pun menjawab, benar, aku memang mencintai Allah." Apakah engkau membenci syetan?" Rabi'ah pun menjawab, "Cintaku kepada Allah telah memalingkan hatiku dari pada membenci syetan," dengan begitu objek cinta bagi Rabi'ah hanyalah Allah semata". 35

\section{Langkah-langkah Mencapai Cinta}

Dalam perjalanan spiritualnya, seorang sufi pasti melalui beberapa tahapan yang harus dilaluinya, tahapan-tahapan tersebut disebut makamat. Jalan itu sangat berat dan untuk berpindah dari satu maqamat ke maqamat yang lain tidak lah mudah, untuk mecapai suatu maqam ke maqam selanjutnya membutuhkan usaha keras dan waktu yang tidak singkat. Terkadang tak jarang seorang calon sufi harus bertahun-tahun tinggal dalam satu maqam. Jalan pendakian tersebut mencakup beberapa maqam, dan mahabbah adalah maqam tertinggi. Begitu juga dengan Rabi'ah Adawiyah, dalam menitis perjalanan dan pengalaman, ia harus melalui beberapa maqam.

Adapun tahapan-tahapan yang dilalui oleh Rabi'ah untuk mencapai maqam mahabbah adalah sebagai berikut:

a. Tobat, Sabar, dan Syukur

Tobat adalah tahapan pertama dalam menempuh tahapantahapan berikutnya. Tobat adalah jalan untuk membersihkan segala

${ }^{35}$ Ibid. h. 129 
Mudaimin, Konsep Cinta Ilahi (Mahabbah) ...| 153

dosa. Tampa adanya tobat seseorang tidak dapat menempuh jalan menuju Allah. Tobat adalah bagian terpenting dalam kehidupan menuju Allah.

Al-Hujwiri berpendapat bahwa terdapat tiga hal yang termasuk dalam tobat; pertama, tobat karena ketidaktaatannya, kedua, memutuskan untuk tidak melakukan dosa lagi, ketiga, segera meninggalkan perbuatan dosa itu. ${ }^{36}$

Rabi'ah memiliki pengertian mendalam tentang dosa dan kebutuhan untuk bertaubat dan memaafkan, dan para penulis sufi, dalam pembahasan masalah tobat lebi dari sekali menyebutkan ajaran Rabi'ah tentang masalah ini." 37

Rabi'ah berkata bahwa Allah adalah penyejuk di dalam dukanya, dan sebagi yang hanya mampu menghapuskan dirinya dari dosa. Kesedihan Rabi'ah atas dosa-dosanya seringkali diulangulangnya.

Rabi'ah mengajarkan bahwa dosa itu sangat menyakitkan, sebab ia mampu memisahkan jiwa dengan yang dicintai. ${ }^{38}$ Keyakinan bahwa dosa adalah penghalang antara seorang hamba dengan tuhannya akan membimbing pada jalan kesedihan yang saleh, yaitu perasaan dosa yang mendalam. Kondisi semacam ini tampak jelas padanya sebagai tanda-tanda kesedihan dari luar, misalnya menangis terus-menerus, cirri semacam ini tampak pada Rabi'ah dan juga para sufi lainnya sebagai tanda kesalehan, penyesalan terhadap dosa-dosa at as perbuatan dan kelalaiannya, dan semua ini akan membakar semua kesedihan terus-menerus sehingga tidak ada tempat lagi bagi kesenangan duniah. Dosa bagi Rabi'ah adalah membangkitkan rasa benci, karena hal itu akan menyebkan terpisahkan dari yang dicintai.

\footnotetext{
${ }^{36}$ Margaret Smith op.cit. h. 62

${ }^{37}$ Ibid. h. 63

${ }^{38}$ Ibid. h. 65
} 
Kesabaran dihubung-hubungkan oleh para penulis sufi sebagai tahap penting di dalam kemajuan kehidupan spiritual, atau mungkin sebagai kualitas penting yang harus dicapai oleh seorang yang suci.

Melalui perjalanan hidup Rabi'ah, dapat dibaca konsep ajarannya tentang sabar dan banyak yang dikisahkan dalam riwayat hidupnya. Rabi'ah adalah seorang yang memiliki kesabaran luar biasa yang tidak dimiliki oleh orang lain pada masanya. Bila kita perhatikan awal hingga akhir, kehidupan Rabi'ah penuh dengan tantangan dan penderitaan, tidak dapat dipunkiri bahwa cobaan ini sangat menyakitkan, namun justru dalam keadaan seperti itulah hatinya mengalami tempuan.

Rabi'ah adalah sosok seorang sufi perempuan yang sangat sabar, dan teguh pandirian dalam menjalani segalah cobaan dan rintangan hidup. Rabi'ah perna berkata, "seandainya keutamaan kesabaran itu laksana seorang laki-laki, maka ia akan berjiwa pemurah". ${ }^{39}$

Bersyukur adalah pelengkap bagi tahap kesabaran, yaitu sesuatu sikap atas semua kebaikan Allah terhadap hamba-Nya. Sebagai mana kualitas-kualitas lainnya yang harus dicapai pada tahap-tahap berbeda di dalam jalur mistik, bersyukur terdiri dari elemen-elemen iman, perasaan dan tindak-tanduk. Iman harus sudi menerima bahwa semua kebaikan itu dari Allah dan itu adalah pemberian Cuma-Cuma dari-Nya. Semua pemberian itu datangnya dari Allah. Dan hal ini haruslah memberikan kebahagiaan kepada sang hamba dan juga menimbulkan sikap kerendahan hati di hadapan sang pemberi, bahkan dalam menjalani penderitaan kita pun harus bersyukur. Perasaan bahagia dan kerendahan hati ini akan membimbing pada suatu tindak-tanduk, dan hamba penerima kebaikan itu akan melakukan segala tindakannya sesuai dengan keinginan-Nya dan menghindari semua larangan-Nya. ${ }^{40}$

\footnotetext{
${ }^{39}$ Syamsun Ni'am, op.cit. h. 59

${ }^{40}$ Margaret Smith, op.cit. h.68
} 
Mudaimin, Konsep Cinta Ilahi (Mahabbah) ...| 155

Rabi'ah memiliki iman yang menganggap bahwa semua pemberian berasal dari Allah sebagai sang pemberi, dan menganggap bahwa penderitaan dan ketidak beruntungan itu merupakan secercah kebaikan dan kebahagiaan. ${ }^{41}$ Imannya telah membimbing pada suatu kebahagiaan dalam menjalani hukuman dari Allah yang ia anggap sebagai kebaikan-nya, dan bersikap rendah hati menerima semua yang diberikan-Nya, dan dari sikap ini membimbing pada tindakan beribadat dan bersyukur, dan keinginan yang mendalam untuk memandang sang pemberi tersebut, dimana semua pemberian itu mendorong pada keinginan penyatuan yang mendalam, selamanya, dengan sang pemberi itu.

b. Raja' dan khauf

Al-Hujwiri menganggap bahwa harapan dan rasa takut benar sangat penting bagi manusia di dunia, dan menganggapnya bagaikan dua pilar keimanan. Mereka yang merasa takut, akan beribadat kepada Allah seakan-akan takut terpisahkan dari-Nya, dan bagi mereka yang memiliki harapan, beribadat kepada Allah dengan penuh harap akan dapat menyatu dengan-Nya. ${ }^{42}$

As-sarraj menyatakan bahwa "harapan dan rasa takut bagaikan dua sayap dimana tampa keduanya, kerja seorang sufi tidak akan berhasil. Rasa takut adalah seperti sebuah tempat dalam kegelapan, dimana jiwa mengembara, liar, selalu mencari jalan untuk keluar". ${ }^{43}$ Dan disaat harapan datang untuk meneranginya, jiwa akan menuju kesuatu tempat yang menyenangkan, dan denga demikian, rahmat akan dapat diraih. Hati terkadang merupakan budak di dalam kegelapan rasa takut, dan harapan terikat bersama-sama menjadi satu. Cinta tidak akan sempurnah tampa rasa takut, rasa takut tidak
${ }^{41}$ Ibid. h. 72
${ }^{42}$ Ibid. h. 75
${ }^{43}$ Ibid. h. $79-80$ 
akan sempurna tampa harapan, dan harapan pun tidak akan sempurna tampa rasa taku.

Bagi Rabi'ah pada tahap ini dikisahkan, bahwa ia telah menjadi subyek dari rasa takut ini, dan pengaruhnya tampak padanya saat disebutkan neraka. Hal ini disebabkan karena kepercayaan pada hari pengadilan nanti, yang pasti akan dilalui oleh orang-orang yang berdosa, suatu keputusan dimana ia dalam keadaan yang lebih lemah. Ia merasa takut apabila ia ditakdirkan harus menghadapi masa itu, dan pada suatu saat ia berdo'a bahwa "ia tidak akan dihukum di neraka dan terbujuk oleh pemikiran jahat". ${ }^{44}$

Meskipun begitu, kesimpulan dari permasalahan ini adalah bahwa bentuk yang paling agung dari rasa takut ini adalah objek itu sendiri (Allah), bukannya hukuman atau bahkan dosa, tetapi Allah sendirilah yang menjadi objek rasa takut, yaitu rasa takut apabila jiwa itu akan dicabut selamanya dari keindahan Allah yang abadi.

Rabi'ah memiliki alasan bahwa takut akan hukuman atau harapan terhadap penghargaan (pahala) menjadi sama-sama tidak berharga lagi bagi seorang sufi. Dalam suatu peristiwa yang diceritakan oleh Aflaki, “Tampak Rabi'ah sangat berusaha untuk melepaskan kedua alasan itu, sebagai rintangan-rintangan mencapai tujuan utama seorang sufi. Lagi pula Rabi'ah berpendapat, adalah seorang hamba yang bodoh apabilah dalam beribadat ,kepada Allah selalu dilandasi pemikiran untuk melepaskan diri dari hukuman dan untuk meraih penghargaan (pahala), baginya hanya Allah saja yang perlu ditakuti dengan penuh ta'zim dikarenakan kesucian-Nya, dan sama bagi dirinya, harapan hanya kepada Allah semata, dalam bayang-bayang keindahan-Nya". ${ }^{45}$

c. Fakir dan zuhud

\footnotetext{
${ }^{44}$ Media Zainal Bahri, MA. Menembus Tirai Kesendirian-Nya Mengurai Maqamat dan Ahwal Dalam Tradis Sufi (Cet. I; Jakarta, Putra Grapari 2005)h. 90 ${ }^{45}$ Margaret Smith, opcit. h. 81
} 
Kefakiran adalah dianggap maqam penting dalam kajian tasawuf. Kemiskinan banyak dilakukan oleh para sufi, tetapi di sini kemiskinan yang dilakukan hanya demi Allah. Abu Muhammad alJurari berkata, "fakir ialah hendaknya kamu tidak mencari sesuatu yang tidak ada pada dirimu, sehinggu kamu kehilangan sesuatu yang ada pada dirimu, dan hendakla kamu tidak usa mencari rezeki-rezeki kecuali kamu takut tidak dapat menegakkan kewajiban". ${ }^{46}$

Spirit kemiskinan pun decerap oleh dunia sufi, yang begiti diidamkan Rabi'ah, semenjak ia belum menjadi seorang zahid, maupun saat ia menyadari maknanya.

Aththar menceritakan bagaimana Rabi'ah pada suatu kesempatan di dalam perjalanan melaksanakan ibadah haji dan tiba di Arafah, ia mendengar suara Allah berkata padanya:

"Wahai engkau yang selalu memohon, apa yang engkau inginkan dari-ku? Jika aku yang engkau inginkan, maka akan aku tunjukkan sebuah kilatan kebesaran- $\mathrm{Ku}$ (tetapi dengan itu) engkau akan hancur lulu." Lalu ia menjawab, "ya Allah Yang Maha Agung, Rabi'ah tidaklah memiliki arti untuk meraih tingkatan setinggi itu, yang aku inginkan adalah setitik kemiskinan." 47

Yang dimaksud kemiskinan di sini adalah menunjukkan suatu keadaan yang benar-benar kehilangan diri sendiri, sangat sulit intuk dicapai, dan tidak akan membimbing pada jalan penyatuan, kecuali apa bila benar-benar sempurna, dan bahkan akan menjadikan para sufi itu subjek dari kegelapan malam dalam jiwa sebelum meraih penyatuan. Penyatuan yang demikian itu hanya dapat dilakukan oleh seorang yang benar-benar berkemampuan meninggalkan semua atribut jati diri. ${ }^{48}$

\footnotetext{
${ }^{46}$ Syamsun Ni'am, op.cit. h. 68

${ }^{47}$ Margaret Smith, op.cit. h. 86

${ }^{48}$ Ibid. h. 87
} 
158 Rausyan Fikr, Vol. 16 No. 1 Juni 2020: 133-162.

Penolakan itu asketisisme (zuhud), dianggap sebagai persamaan sisi dari konsep agung kemiskinan itu. "Tahap pertama zuhud ini, bagi kaum sufi, sebagai permulaan dan mewakili kehidupan penyucian, apabila jiwa telah disucikan dari semua nafsu, dan seorang sufi telah "Suci dari sejati diri sendiri bagaikan terpisahnya antara api dengan asap", maka barulah dimulai perjalanan menuju Allah", 49

d. Mahabbah dan Ma'rifat

Cinta dianggap tahap tertinggi yang dapat dicapai oleh seorang ahli tasawuf. Termasuk didalamnya kepuasan hati (ridha), kerinduan (syauq) dan keintiman (uns). Ridha mewakili ketaatan tanpa disertai adanya penyangkalan, dari seorang pecinta terhadap kehendak yang dicintai, syauq adalah kerinduan sang pecinta untuk bertemu dengan sang kekasi, dan uns adalah hubungan intin yang terjalin antara dua kekasi spiritual itu. "Dari tahap cinta ini seorang sufi akan lansung mencapai ma'rifat, dimana ia akan mampu menyingkap keindahan Allah dan dapat menyatu dengan-Nya" ${ }^{50}$

Ajaran cinta dikembangkan Rabi'ah merupakan pengembangan dari konsep yang diajarkan Hasan al-Bashri, dimana Hasan al-Bashri semula membawa ajaran khauf dan raja, yang kemudian dikembangkan lagi oleh Rabi'ah, yaitu kesuatu tingkatan mahabbah. Hasan al-Bashri dalam mengapdi kepada Allah karena didasari rasa takut kepada neraka dan harapan akan surga. Namun Rabi'ah jauh dari kedua hal itu. Ia mencintai Allah bukan karena takut neraka, dan tidak juga mengharap surga, namun ia mencintai Allah semata seperti dalam syairnya:

"Ya Allah, jika Aku menyembah-Mu, karena takut pada neraka, maka bakarlah aku di dalam neraka-Mu. Dan jika aku menyembah-Mu karena mengharapkan surga, maka campakanlah aku dari dalam surga-Mu, tetapi jika aku menyemba-Mu demi engkau semata, janganlah Enkau

\footnotetext{
49 Ibid. h. 87

${ }^{50}$ Syamsung Ni'am, op.cit. h. 74
} 
Mudaimin, Konsep Cinta Ilahi (Mahabbah) ...| 159

enggan memperlihatkan keindahan wajah-Mu yang abadi kepadaku". ${ }^{51}$

Aththar menyebutkan bahwa dia antara ucapan-ucapan Rabi'ah tentang demikian mendalamnya cinta kepada Allah, yaitu pada suatu hari Rabi' ah ditanya,

Dengan cinta yang demikian itu, setelah melewati tahaptahap sebelumnya, seorang sufi mampu meraih ma'rifat sufistik dan hati yang telah di penuhi oleh rahmat-Nya. Pengetahuan itu datang langsung sebagai pemberian dari Allah tanpa hijab. Dengan mata yang telah dipenuhi oleh ma'rifat, para sufi akan mempu menatap penyaksian itu, dan memandang-Nya dengan asyik terpesona dalam penyatuan dengan yang suci. Itulah tujuan akhir dari pencarian atau pengembaraan jiwa, akhir dari jalur, tercapai sudah, tidak dengan penghancuran, tetapi kekhusyukan dan perubahan, sehingga jiwa akan diubah kedalam penyaksian suci, dan menjadi bagian dari Allah itu sendiri, di dalam tempat dan kehidupan bersama-Nya untuk selamanya.

\section{Tujuan Cinta}

Mencintai dan dicintai bisa membuat seseorang menjadi bahagia. Meskipun tidak ada ukuran pastinya dan tidak bisa dijelaskan dengan kata-kata, namun perasaan cinta dapat membuat seseorang menjadi bahagia dalam hidupnya. Dalam perjalanan hidup ini dan kehidupan manusia, tidak akan bisa lepas dari orientasi atau tujuan hidup itu sendiri. Bila ditanyakan, untuk apakah manusia hidup didunia ini, suda barang tentu jawabanya adalah untuk mencari kebahagiaan. Walaupun kenyataannya, tidak semua orang mengerti dan memahami arti kebahagiaan itu sendiri, apakah itu kebahagiaan yang bersifat sementara atau kebahagiaan yang bersifat kekal dan abadi.

${ }^{51}$ Dr. Asmaran As. M.A. Pengantar Studi Tasawuf(Cet II; Jakarta, PT Raja Grapindo Persada. 1994), h. 273 
160 Rausyan Fikr, Vol. 16 No. 1 Juni 2020: 133-162.

Ada beberapa pengertian dan pemahaman mengenai kebahagiian, dengan melihat pemenuhan kebutuhan masing-masing. Kebahagiaan memiliki kaida sebanyak orang, sebanyak penderitaan, sebanyak pengalaman, dan sebanyak kekecewaan.

Adapun menurut Rabi'ah Al-Adawiah, kebahagiaan tertinggi adalah terletak pada kasyf, yaitu terbukanya hijab untuk bisa melihat Allah, seperti dalam syairnya tentang konsep cintanya yang kedua, yaitu:

"Cinta karena diri-Mu adalah keadaan-Mu

Mengunkapkan tabir hingga Engkau kulihat". ${ }^{2}$

Dari pemaparan di atas dapat di lihat tujuan cinta Rabi'ah adalah pencarian kasyf itu sendiri, sehingga tak tampak sedikit pun yang selain-Nya.

\section{PENUTUP}

Setelah melakukan penkajian mengenai cinta Ilahi perspektif Rabi'ah Adawiyah, maka dapat disimpulkan konsep cinta ilahi yang di tawarkan Rabi'ah Al-Adawiah adalah cinta yang menutupi cinta yang lain selain Sang Kekasih atau Yang Dicintai. Rabi'ah memisahkan dirinya dari semua mahluk ciptaan Allah termasuk Nabinya, agar tidak dapat menarik diri dari sang kekasih pecipta alam semesta. Cinta seorang Rabi'ah tidak ada pamrih sama sekali dan tidak mengharapkan balasan baik yang berupa ganjaran maupun pembebasan hukuman, tetapi yang dicari hanyalah melakukan segala perintahnya dan melakukan segala keinginan Allah dan menyempurnakannya.

Menurut Rabi'ah Adawiyah cinta Ilahi (Mahabbah) Merupakan tujuan akhir dari kehidupan dan merupakan maqam tertinggi. Rabi'ah membagi konsep cintanya dalam dua macam yaitu, cinta diri karena selalu ingat kepada Yang Tercinta (Allah) dan larutnya Rabi'ah dalam mengingat Allah dari pada Berinteraksi

${ }^{52}$ Dr. Asmaran As. M.A. op.cit, h. 269 
Mudaimin, Konsep Cinta Ilahi (Mahabbah) ...| 161

dengan selain diri-nya, dan cinta kepada Allah dimana keadaan Yang Tercinta (Tuhan) yang bersedia membukakan tabir-Nya kepada sang pecinta dan Dia patut dicintai.

Cara Rabi'ah Adawiyah mencapai maqam mahabbatullah, adalah dengan melakukan dan mengamalkan tobat, sabar, syukur, raja, khauf, fakir, zuhud, dan mahabbah, setelah mahabbah maka muncullah ma'rifah. Ma'rifah ini merupakan hal yang datang langsung sebagai pemberian atau hadia dari Allah. Ma'rifah itu sendiri adalah terbukanya hijab antara hamba dan Allah (kasf), sehingga ma'rifah merupakan hasil dari mahabbatullah.

\section{DAFTAR PUSTAKA}

Al-Kalabadzi. Ajaran Kaum Sufi. (Cet. I, Bandung: Mizan, 1993)

Annemarie Schimmel. Dimensi Mistik Dalam Islam. (Jakarta: Pustaka Firdaus2003.)

Asy-Syibli. Menyingkap Hati Menghampiri Ilahi. (Bandung: Pustaka Hidayah 1999)

M. Taufik Belajar Mencintai dan Dicintai Allah Dari al-Ghazali (Skripsi- IAIN Palu)

Dr, Abu al-Wafa' al-Ghanimi al-Taftazani. Sufi Dari Zaman ke Zaman, (Cet, I. Bandung, Penerbit Pustaka, 1406 H-1985 M).

Dr. Asmaran As. M.A. Pengantar Studi Tasawuf(Cet II; Jakarta, PT Raja Grapindo Persada. 1994)

Dr. Javad Nurbakhsh. Wanita-Wanita Sufi (Cet. I; Bandung. Penerbit Mizzan, 1996)

https://mojok.co/miq/esai/kelahiran-dan-kematian-rabiah-aladawiyyah/ diakses pada tanggal 16 Mei 2020.

Johan Jafar, mengenal sosok sufis wanita, Rabih, (onlaine)www.cinta ilahi.com) diakses pada tanggal 22 Mei 2020 
162 Rausyan Fikr, Vol. 16 No. 1 Juni 2020: 133-162.

Khoir Mufidul. Rahasia Para Sufi. (Yogyakarta: SKETSA, 2007)

Margaret Smith, Rabi'ah: Pergulatan Spiritual Permpuan (Cet. 1, Surabaya: 2001)

Media Zainal Bahri, MA. Menembus Tirai Kesendirian-Nya Mengurai Maqamat dan Ahwal Dalam Tradis Sufi (Cet. I; Jakarta, Putra Grapari 2005)

Mufidul Khoir, Rahasia Para Sufi (Cet. II; Yogyakarta, Republika, 2007)

Muhammad Bin Asy-Syarif, Nilai Cinta Dalam Al-Qur'an (Solo; PT. Serangkai Pustaka Mandiri 2003)

Muhammad Roy. Tasawuf Madzab Cinta, (Cet. I, Yogyakarta: Penerbit Lingkaran 2009)

Safari MS \& Otto Sukatno, Mahabba: Cinta Rabi'ah Adawiyah (Cet. I; Bandung. Risalah Gusti 2001)

Safari MS \& Otto Sukatno, Mahabba: Cinta Rabi'ah Adawiyah (Cet. I; Bandung. Risalah Gusti 2001)

Syamsun Ni'am. Cinta Ilahi Perspektif Rabi'ah Adawiyah dan Jalaluddin Rumi. (Cet. IV, Surabaya: Risalah Gusti, 2001)

Syamsun Ni'am. Cinta Ilahi Perspektif Rabi'ah Adawiyah dan Jalaluddin Rumi. (Cet. IV, Surabaya: Risalah Gusti, 2001)

Syekh 'Ustman Al-Khubari, kisah Cinta Rabi'ah (Cet.VII; Jogjakarat, Diva Press 2011) 